DOI 10.37882/2223-2982.2020.04-2.03

\title{
ОСОБЕННОСТИ ЭЛЕКТРОННОГО РЕСУРСНОГО ОБЕСПЕЧЕНИЯ ЗАОЧНОЙ ФОРМЫ ОБУЧЕНИЯ
}

\section{FEATURES OF ELECTRONIC TEACHING RESOURCE FOR CORRESPONDENCE STUDENTS}

\section{E. Avdosenko T. Panina A. Kuidin}

Summary: The paper considers the issue of the design and introduction of the effective forms of teaching material presentation in the electronic educational resources, which are an educational base for correspondence students. The objective of the research is to analyze of the acceptable and applicable educational submission formats in the electronic teaching resource for students of correspondence form of education to master the disciple of "Foreign Language". In the course of the recent research, we used the general theoretical method to describe the learning electronic resource structure as well as the methods for analyzing and comparing forms and ways of filling electronic educational resources. As an experiment, in the electronic educational resource various formats for learning material presentation were applied; the method of statistical calculation allowed us to collect the data displaying the dynamics of the quality of discipline mastering.

Keywords: correspondence course, e-learning, distance educational technologies, electronic educational resource, quality of discipline mastering.

\author{
Авдосенко Елена Валериановна \\ к.филол.н., дочент, Иркутский начиональный \\ исследовательский технический университет \\ aev74@mail.ru \\ Панина Татьяна Геннадьевна \\ к.филол.н., доцент, Иркутский государственный \\ университет \\ panina111@mail.ru \\ Куйдин Анатолий Анатольевич \\ Восточно-Сибирский институт экономики и права, \\ 2. Иркутск \\ kuidin.aa@gmail.com
}

Аннотация: На сегодняшний день актуальным является вопрос разработки и внедрения качественных электронных ресурсов, являющихся образовательной базой для студентов заочной формы обучения. Целью данного исследования является анализ возможных и используемых форматов представления учебных материалов в электронном образовательном ресурсе для освоения студентами заочной формы обучения учебной дисциплины «Иностранный язык». В ходе проведенного исследования использовался общетеоретический метод описания структуры учебного электронного образовательного ресурса, а также методы анализа и сравнения форм и способов наполнения электронных образовательных ресурсов. В качестве эксперимента применялись различные форматы представления учебных материалов в электронном образовательном ресурсе, а метод статистического подсчета позволил собрать данные, отображающие динамику качества освоения дисциплины.

Ключевые слова: заочная форма обучения, электронное обучение, дистанционные образовательные технологии, электронный образовательный ресурс, качество освоения дисциплины.

возможностей и потребностей [11, с. 42]. Заочная форма обучения становится, таким образом, одним из основных образовательных звеньев, несмотря на скептическое отношение населения и педагогических работников к данной форме обучения. Подобное отношение объяснялось недостатком эффективных методик обучения, а также отсутствием непосредственного контакта обучающихся и педагогических работников, что при большом проценте самостоятельной работы (85-90\%) негативно отражалось на качестве обучения.

Сегодня критическое восприятие заочной формы обучения уходит в прошлое, а сама форма обучения становится важнейшей составляющей системы непрерывного образования и представляет собой альтернативу для тех групп населения, для которых получение среднего, высшего и дополнительного профессионального образования в очной форме долгое время было затруднительно или даже вообще невозможно. Следует подчеркнуть, что число обучающихся по данной форме обучения не 
только не сокращается, но и постоянно увеличивается. Отмечается, что «за последние семьдесят лет доля студентов, обучающихся по заочной форме обучения, практически удвоилась» [10, с.79; 12, с. 613-614], хотя приоритеты выбора формы обучения могут варьироваться как по регионам, так и внутри отдельной образовательной организации [15]. Современный этап развития заочной формы обучения связан с развитием информационных и коммуникационных технологий [13, с.28]. Заочное обучение отходит от одностороннего взаимодействия и переходит на двухстороннюю связь в различных форматах в синхронном и асинхронном режимах [4, с. 158]. В Федеральный закон «Об образовании в РФ» N 273-Ф3 вводятся такие понятия как «электронное обучение» и «дистанционные образовательные технологии», предоставляя образовательным организациям среднего и высшего профессионального образования право применять электронное обучение и использовать дистанционные образовательные технологии для реализации образовательных программ для всех форм получения образования или при их сочетании. Согласно опросу, студенты заочной формы обучения воспринимают данные изменения положительно. Данная форма получения образования приобретает все большую популярность, поскольку в целом «с каждым годом интерес к дистанционному образованию растет, так как в период формирования единого глобального и информационного пространства, именно такая форма обучения отвечает запросам времени» [6, с. 89]. Применение электронного обучения и дистанционных образовательных технологий не только дает возможность обучения, переобучения или повышения квалификации без отрыва от основного вида деятельности, но и является в некоторых случаях единственной возможностью получения качественного образования для отдельных категорий обучающихся [8, с. $116 ; 9$, с. 152-153; 13, с.30-32].

Вузы начинают внедрять системы дистанционного обучения (Moodle, iLogos, Mirapolis Virtual Room, Гекадем), включающие методики, технологии, приемы и средства для организации учебного процесса по заочной форме обучения. Платформой для организации учебного процесса по заочной форме обучения с применением электронного обучения и дистанционных образовательных технологий является, как правило, образовательный портал образовательной организации, где создаются и внедряются в учебный процесс электронные образовательные ресурсы. Электронный образовательный ресурс (далее ЭОР), как объект научно-педагогического труда, включает в себя образовательный контент, программные компоненты и метаданные о них, обеспечивает передачу информации и взаимодействие участников образовательного процесса, способствуя формированию необходимых компетенций [7].

Разработка и внедрение электронных образователь- ных ресурсов по различным учебным дисциплинам является уже реальностью, но открытым остается вопрос качества данных ресурсов $[1 ; 14 ; 16]$, призванного обеспечить высокий уровень получаемых знаний и умений будущими специалистами. Следовательно, основное внимание при разработке ЭОР должно уделяться не только качественному содержанию учебных материалов, но и формату их представления в электронном образовательном ресурсе. Данной проблематикой обусловлена цель представленного исследования, заключающегося в анализе форм и способов наполнения электронных образовательных ресурсов, влияющих на динамику показателей качества освоения дисциплины.

Опираясь на опыт работы, и учитывая основные принципы формирования элементов ЭОР, такие как адаптивность, доступность, интерактивность, мобильность, модульность, наглядность [1, с. 33-34], электронный образовательный ресурс по заочной форме обучения может объединить все виды учебной деятельности в три основных блока: общий раздел, методическое обеспечение организации изучения дисциплины (теоретический и практический разделы) и методическое обеспечение системы оценки качества освоения дисциплины (контрольный раздел).

Качественный учебный ЭОР [1] позволит «оптимизировать учебный процесс студентов», т.к. вся необходимая информация по дисциплине (требования к освоению дисциплины, практические задания, тесты, контрольные задания и др.) аккумулированы в едином информационном образовательном пространстве [17, с. 357-358]

Первый блок представляет собой общий раздел по дисциплине, включает в себя общие сведения о дисциплине и может содержать: пояснительную записку о дисциплине и требованиях по ее изучению; основные источники по дисциплине; вопросы к зачету, экзамену и др. Форматами представления учебного материала данного блока могут быть текстовый, аудио- или видеоформаты. Способами реализации на образовательном портале могут выступить такие интерактивные образовательные модули как «книга», «пояснение», «страница», «файл», «гиперссылка» (название модулей представлено на примере системы дистанционного обучения Moodle).

Второй блок, методическое обеспечение организаиии изучения дисциплины, включает в себя:

- материалы для теоретического изучения (представленные по темам учебной дисциплины);

- комплекс материалов для повторения и закрепления пройденного материала.

Теоретический материал содержит материалы для теоретического изучения учебной дисциплины в объ- 
еме, утверждённым учебным планом. В ЭОР теоретический материал может быть представлен отдельным (теоретическим) разделом или выделяться в отдельных тематических разделах в виде логически завершенных учебных блоков. Практический материал, как комплекс материалов для повторения и закрепления пройденного материала, можно также обособить отдельным разделом или сделать частью тематических разделов.

Материал для теоретического изучения может быть представлен в ЭОР в текстовом формате, единственной возможностью более века назад, а также размещен, активно используемыми в конце XX века, в форматах кейс-технологий и TV-технологий [8, с.117]. Следует подчеркнуть, что, несмотря на указанные возможности, «текст учебного пособия не позволяет воспроизводить вузовскую атмосферу» [10, с. 79-80] и потому современными тенденциями с начала XXI века становятся сетевые технологии [там же], а форматами представления теоретического материала аудио- и видео-форматы, дающие возможность мобильного и интерактивного освоения материала (в удобное время, параллельно с другими видами деятельности) [8, с. 116-117; 13, с. 31-32].

Представить теоретический материал на образовательном портале можно в любом из возможных форматов с помощью разных интерактивных образовательных модулей: «лекция», «страница», «файл», «гиперссылка», «Wiki» и др. Для того, чтобы наполнить ЭОР по заочной форме обучения качественным контентом, следует использовать текстовый формат только в виде пояснений, описаний, сопровождений и дополнительного материала. Необходимо подкреплять теоретический материал глоссариями, ссылками на источники из электронной библиотечной системы образовательной организации, а также иллюстрационными и демонстрационными материалами. Демонстрационные материалы могут быть представлены с помощью интерактивных образовательных модулей: «книга», «страница», «файл», «Wiki», а ссылки на внешние источники с помощью интерактивных модулей «гиперссылка» или «файл» (в случае использования авторского источника). Глоссарий размещается в виде соответствующего модуля «глоссарий».

Практический материал состоит из практических заданий и тестов и должен быть составлен с возможностью многократного выполнения, доступа к правильным вариантам ответов в качестве самоконтроля, включая комментарии к неправильным ответам. Практические задания размещаются в виде заданий ручной или автоматической проверки интерактивными образовательными модулями «задание», «семинар», «форум» (для заданий ручной проверки) и модулем «тест» (для заданий автоматической проверки).

Современные программные средства и технологии дают участникам образовательного процесса также возможность взаимодействия простыми и удобными способами, ведь практический раздел должен обязательно включать интерактивную составляющую для возможности взаимодействия преподавателей и обучающихся. В ЭОР данная составляющая реализуется, в основном, такими модулями как «форум», «чат» и «обмен сообщений». Кроме того, образовательным организациям для проведения семинарских занятий в режиме веб-конференций или онлайн-трансляций предлагается сегодня широкий спектр программных обеспечений, среди которых в нашей стране наиболее известны приложения Adobe Connect и BigBlueButton. Внедрение данных программных обеспечений, легко интегрирующих с системами дистанционного обучения (в частности с LMS Moodle), безусловно, повышает эффективность образовательного процесса, но ставит ряд вопросов, необходимых для решения при активном внедрении стрим-технологий в образовательный процесс. В частности: формирование контента и организация процесса, техническое сопровождение, подготовка преподавателей и студентов и др. [2, с. $240-242 ; 3$, с.35].

Второму блоку, а именно методическому обеспечению организации изучения дисциплины, следует уделять особое внимание при наполнении ЭОР по заочной форме обучения. Качественный контент данного блока с логической структурой, аудио- или видео-форматами представления теоретического материала, подкрепленного иллюстрациями, таблицами и схемами, а также вариативными практическими заданиями ручной и автоматической проверки позволяет говорить о повышении качества образовательного процесса.

Третий блок представляет собой методическое обеспечение системы оценки качества освоения дисциплины и включает в себя фонды оценочных средств для текущей и промежуточной аттестации обучающихся. Контролирующие задания должны касаться всех базовых проблем изучаемой дисциплины и могут реализоваться на образовательном портале с помощью интерактивных образовательных модулей «задание», «тест», «глоссарий», «форум», предполагая как ручную, так и автоматическую проверку.

Промежуточная аттестация содержит различные виды контроля, предусмотренные учебным планом: зачет, дифференцированный зачет, экзамен, курсовая работа. При организации промежуточного контроля с применением электронного обучения и дистанционных образовательных технологий обучающийся выполняет зачетное или экзаменационное задание, представленное на ЭОР, в сроки, установленные учебным расписанием. В случае пересдачи зачета (экзамена) обучающемуся даются дополнительные попытки в ЭОР для выполнения (контрольных, зачетных или экзаменационных) заданий. 
Итоговая оценка за дисциплину при приеме промежуточного контроля с использованием дистанционных образовательных технологий составляет среднюю оценку за все, представленные в ЭОР, контрольные и итоговые задания. Обучающийся, освоивший содержание дисциплины менее чем на $60 \%$ и получивший «незачтено» или «неудовлетворительно» по дисциплине, имеет право повторно пересдать дисциплину до начала следующей сессии. Для возможности самоконтроля и, в конечном итоге для повышения мотивации и мобильности, обучающиеся по заочной форме обучения с применением электронного обучения и дистанционных образовательных технологий имеют доступ к журналу успеваемости ЭОР, где фиксируются все оценки, как по отдельным темам, так и по курсу в целом [5, с. 231-232; 17, c. 358].

В данной работе хотелось бы представить анализ ЭОР по дисциплине «Иностранный язык», созданного для студентов заочной формы обучения в системе дистанционного обучения Moodle (URL: https://el.istu.edu/ course/view.php?id=32).

Ресурс постоянно обновляется и расширяется, его учебный предметный контент и форматы представления учебного материала дополняются и совершенствуются. Созданный в 2016-2017 учебном году, ЭОР изначально включал контрольный раздел, в котором была размещена контрольная работа и контрольный тест. Контрольная работа, как задание ручной проверки, была представлена образовательным модулем «задание», а грамматический тест, как задание автоматической проверки, интерактивно-образовательным модулем «тест». Контрольный тест содержал ограниченное количество вопросов однотипной формы в виде вопроса «множе- ственного выбора», предполагая однократное выполнение с ограничением по времени.

Теоретический материл, представленный в текстовом формате образовательными модулями «страница» и «файл», включал в себя грамматический справочник по изучению иностранного (немецкого) языка и ряд приложений с речевыми клише (речевыми образцами для передачи содержания текста на иностранном языке, для выражения личностного высказывания для построения смысловых переходов и др.).

В 2017-2018 учебном году появляется уже общий раздел ЭОР, куда добавляются ссылки на учебники и учебные пособия из электронно-библиотечной системы, а также ссылки на внешние интернет-ресурсы. В ЭОР выделяется грамматический раздел, где теоретический материал структурируется и иллюстрируется поясняющими таблицами и схемами. Банк тестовых вопросов увеличивается, предполагая многократное повторение материала. Обучающиеся получают возможность выполнять тренировочные тесты неограниченное количество раз, а после выполнения теста увидеть результат и правильные ответы.

В 2018-2019 учебном году ЭОР включает уже все три блока: общий раздел, методическое обеспечение организации изучения дисциплины, представленное грамматическим и коммуникативным разделом и методическое обеспечение организации изучения дисциплины в виде контрольного раздела.

В первом блоке дается общая информация по изучению дисциплины в виде пояснительной записки и вопросами к зачету или экзамену. Здесь же представлены

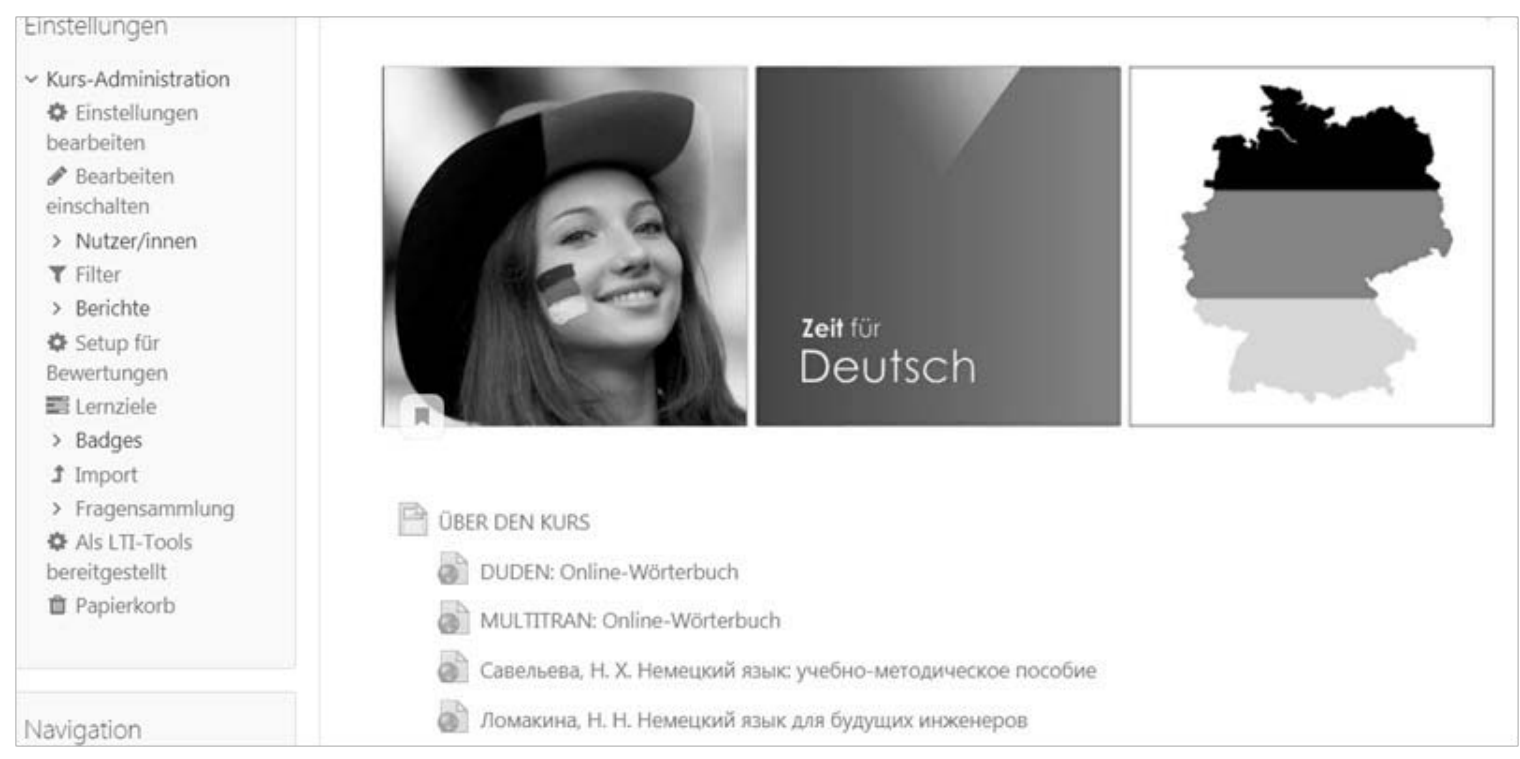

Рис. 1. Фрагмент общего раздела ЭОР «Иностранный язык» 
ссылки на учебные материалы из электронно-библиотечной системы и ссылки на словари в интернет-ресурcax.

Второй блок включает в себя грамматический и коммуникативный разделы. Теоретический материал в грамматическом разделе представлен уже в видео-формате, а материал в текстовом формате используется, как иллюстрационный, и реализуется в ЭОР образовательным модулем «книга» в виде таблиц и схем. В тестовых лексико-грамматических заданиях используются уже разнообразные форматы вопросов и многообразные сценарии тестирования. В отдельных заданиях представлены комментарии, поэтому в процессе прохождения тестового задания в режиме тренинга можно узнать не только, в каком вопросе ошибка и какой вариант правильный, а также получить доступ к правилу по теме. Появляются также элементы для методической и технической поддержки обучающихся, которые реализуются на ЭОР модулем «форум».

Третий блок сформирован из контрольных заданий как ручной, так и автоматической проверки для контроля таких видов речевой деятельности как «Чтение» и «Письмо». Контрольный лексико-грамматический тест, также как и, в 2016-2017 учебном году ограничен по времени и по количеству попыток, но по сравнению с 2016-2017 учебным годом, банк тестовых вопросов увеличился до 1200 разнообразных тестовых заданий. Следовательно, у обучающихся появляется возможность подготовиться к контрольному тесту при выполнении практических тестовых заданий, так как в современных системах дистанционного обучения общий банк тестовых вопросов.

Критерием эффективности внедряемых учебных материалов, а также форматов их представления является

\section{Das 1. Studienjahr}

Theorie "Präsens"

Test "Präsens": Teil A

Test "Präsens": Teil B

Theorie "Haben, sein, werden в Präsens"

Test "Haben, sein, werden в Prăsens"

Theorie "Verben mit Prăfixen"

Test "Verben mit Präfixen"

Theorie "Modalverben in Präsens"

Рис. 2. Фрагмент грамматического раздела

такой показатель как «качество освоения дисциплины», хотя данная величина относительна, и на нее может влиять ряд факторов, например, таких как, довузовская подготовка обучающихся, эмоционально-психологическое состояние, сформированность IT-компетенций и др. Следовательно, показатель качества является многофакторным и требует комплексного оценивания. Тем не менее, установленным является тот факт, что качественный контент ЭОР является ключевой составляющей для формирования иноязычной коммуникативной компетенции в свете требований современных образовательных стандартов. Формат представления учебного материала также способствует положительной динамике показателя качества знаний. В современных системах дистанционного обучения, например в LMS Moodle, автоматически заложены настройки отчетов работы пользователей с ЭОР, что позволяет преподавателю увидеть анализ по отдельным показателям или по курсу в целом за определенный период обучения. Данные инструментарии позволяют легко провести аналитику (выгружая данные оцениваемых элементов за определенный период) и отследить траекторию изменения учебных показателей. Анализируя возможные форматы представления учебных материалов в ЭОР для студентов заочной формы обучения, мы использовали отчеты по представленному ранее ЭОР и проанализировали показатели за трёхлетний период. В первую очередь, отмечена активность выполнения тренировочных тестовых заданий (Puc. 4).

Представленный электронный образовательный ресурс охватывает формирование только отдельных видов речевой деятельности. Тем не менее, наблюдается положительная динамика качественного освоения дисциплины (Рuc.5) у студентов заочной формы обучения при сдаче экзамена по дисциплине «Иностранный язык».

\section{PRÜFUNGSVORBEREITUNG}

TEST 1_Das 1. Studienjahr

AUFGABEN 1-5_Das 1. Studenjahr

TEXTE 1-5_Das 1. Studienjahr

TEST 2_Das 2. Studienjahr

AUFGABEN 6-10_Das 2. Studenjahr

TEXTE 6-10_Das 2 Studienjahr

Рис. 3. Фрагмент контрольного раздела 


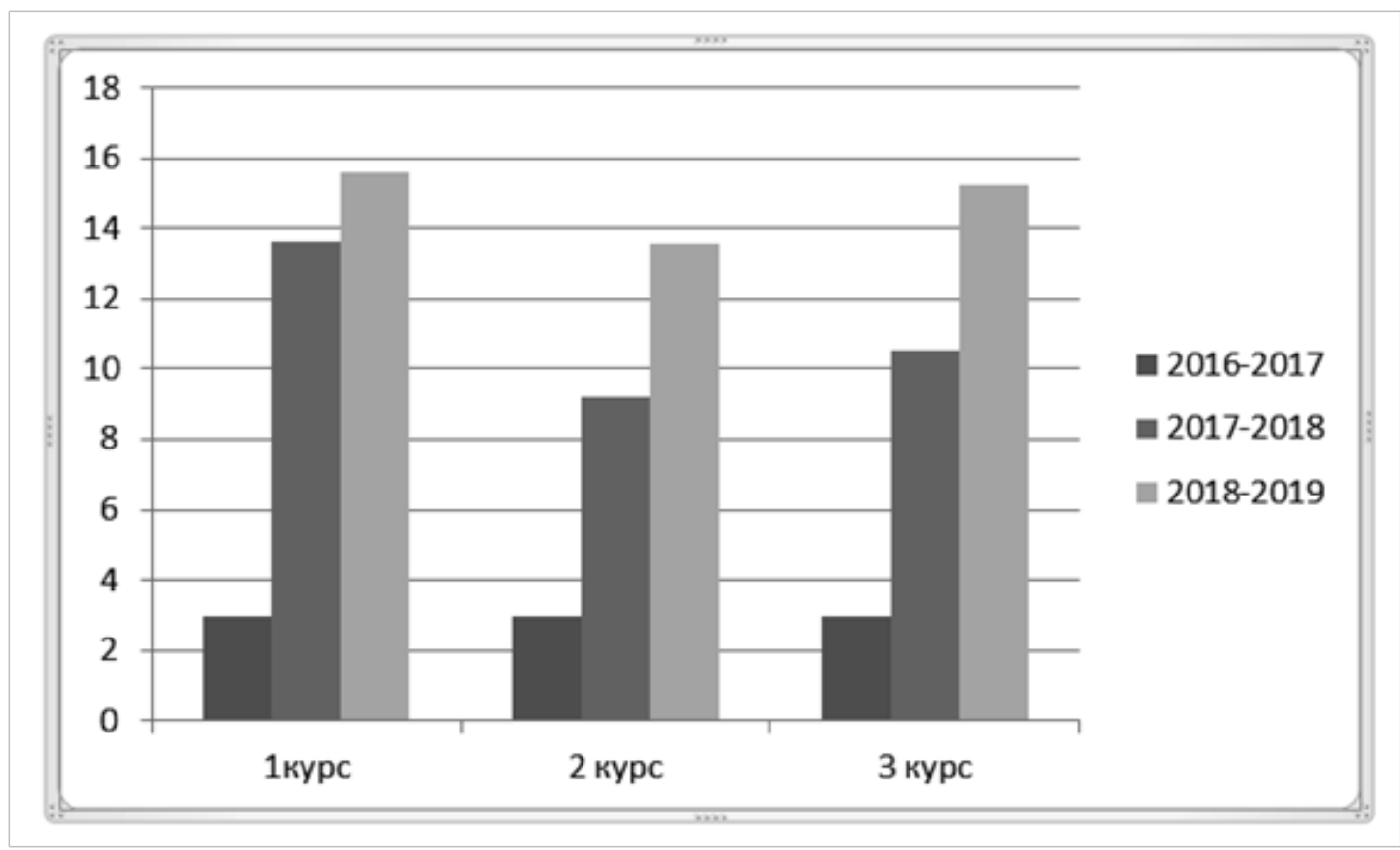

Рис. 4. Среднее количество попыток от общего числа обучающихся

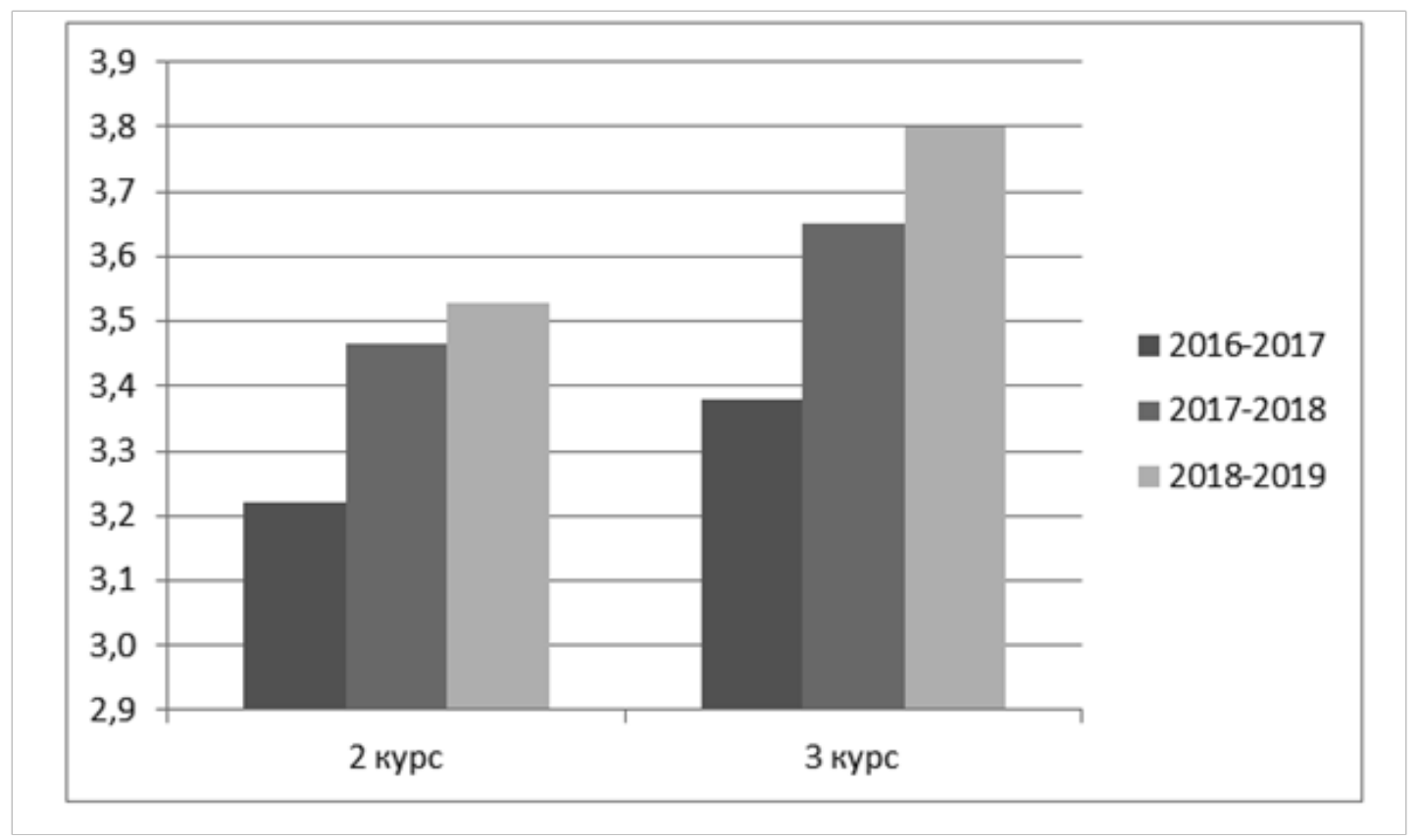

Рис.5. Показатель качества освоения дисциплины

Подводя итоги представленного исследования, хотелось бы подчеркнуть, что электронное обучение и дистанционные образовательные технологии, являясь реалиями современного образовательного процесса, создают успешную и эффективную основу для студентов заочной формы обучения. Качество приобретаемых компетенций - предметных знаний, умений и навыков - в значительной степени коррелирует с предлагаемым форматом и содержанием учебного материала. Регулярное обновление, актуализация и модернизация электронных образовательных ресурсов посредством современных методик и технологий обеспечивает высокое качество и эффективную организацию образовательного процесса обучающихся, выбравших для себя заочную форму обучения с применением электронного обучения и дистанционных образовательных технологий. 


\section{ЛИТЕРАТУРА}

1. Авдосенко Е.В., Куйдин А.А. Оценка качества учебного электронного образовательного ресурса // Открытое и дистанционное образование. Томск: 000 «Издательство ТГУ», 2016. № 4(64). С.31-38.

2. Антонова Н.Л., Меренков А.В. Модель «перевернутого обучения» в системе высшей школы: проблемы и противоречия // Интеграция образования, 2018. T.22. №2 (91). 237-247.

3. Арбузов С.С., Константинов А.Н. Использование стрим-технологий в образовательном процессе при обучении студентов в дистанционной форме // Педагогическое образование в России, 2018. №8. С.34-41.

4. Бабаева М.А., Смык А.Ф. Заочное обучение: исторический путь к МООК // Высшее образование в России. Москва: Московский политехнический университет, 2018. №4. С.156-164.

5. Белова Л.А., Быстрай Е.Б., Слабышева А.В. Развитие механизмов самоконтроля у студентов вузов при изучении иностранного языка // Перспективы науки и образования, 2019. №5 (41). С.229-242.

6. Блоховцева Г.Г., Маликова Т.Л., Симоненко А.А. Перспективы развития дистанционного обучения // Новая наука, 2016. №118-3. С.89-92.

7. ГОСТ Р 53620-2009. Информационно-коммуникационные технологии в образовании. Электронные образовательные ресурсы. Общие положения // Электронный фонд правовой и нормативно-технической документации. URL: http://docs.cntd.ru/document/1200082196 [дата 0бращения: 12.01.2020].

8. Журавлева 0.И. Перспективы развития дистанционных технологий открытого образования в современной высшей школе // Проблемы современного педагогического образования, 2019. № 63-1. С. 115-118.

9. Калабихина И.Е., Бирюкова С.С., Макаренцева А.О. Реализация программы содействия занятости через профессиональное переобучение женщин с маленькими детьми в городе Москве // Мир России. Социология. Этнология. 2018. №2. С.136-162.

10. Кликунов Н.Д. Влияние сетевых технологий на трансформацию высшего образования в России // Высшее образование в России, 2017. №3. С. 78-85.

11. Мацибора М.Г. Из истории становления заочного образования в России // Кострома: Вестник КГУ, 2007. №3. С.42-45.

12. Наумов В.И. Использование дистанционных образовательных технологий в подготовке студентов заочной формы обучения // 0бразовательные технологии и общество. Казань: Казанский национальный исследовательский технологический университет, 2015. Том: 18. №1. С.612-620.

13. Неустроев С.С. Об организации современного электронного обучения для детей и взрослых с ограниченными возможностями здоровья // Управление образованием: теория и практика, 2017. №1 (25). С.28-35.

14. Титова С.В., Александрова К.В. Теоретико-методические основы использования электронных образовательных ресурсов в обучении иностранному языку // Вестник Московского университета. Москва: Издательство: Московский государственный университет. Серия 19. Лингвистика и межкультурная коммуникация, 2018. №3. С. 113-123.

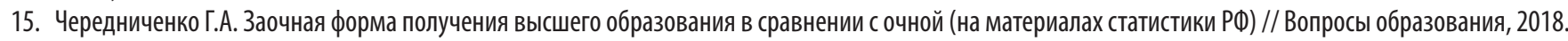
№2. C. 254-280.

16. Шевцов В.И. Методологические основы экспертной оценки электронных образовательных ресурсов для системы дистанционного обучения медицинского персонала МЧС России // Перспективы науки и образования, 2018. №1 (31). С.23-28.

17. Широколобова А.Г., Ларионова Ю.С., Березина А.С. Использование технологий е-learning в организации самостоятельной работы по иностранному языку студентов заочной формы обучения // Филологические науки. Вопросы теории и практики, 2019. №3. С.353-358.

\footnotetext{
(c) Авдосенко Елена Валериановна (aev74@mail.ru), Панина Татьяна Геннадьевна (panina111@mail.ru), Куйдин Анатолий Анатольевич (kuidin.aa@gmail.com).

Журнал «Современная наука: актуальные проблемы теории и практики»
} 